\title{
Silencing of RBP-JK promotes the differentiation of bone marrow mesenchymal stem cells into vascular endothelial cells
}

\author{
ZHENGLIANG LUO ${ }^{*}$, YONG DAI ${ }^{1 *}, \mathrm{MIN} \mathrm{CHEN}^{2}, \mathrm{CHEN} \mathrm{ZHU}^{2}$, \\ KERONG WU ${ }^{2}$, GUOYUAN $\mathrm{LI}^{2}$ and XIFU $\mathrm{SHANG}^{2}$ \\ ${ }^{1}$ Shandong University, Jinan, Shandong 250012; ${ }^{2}$ Department of Orthopaedic Surgery, \\ Anhui Provincial Hospital, Hefei, Anhui 230001, P.R. China
}

Received April 15, 2019; Accepted August 8, 2019

DOI: $10.3892 / \mathrm{mmr} .2019 .10803$

\begin{abstract}
Bone marrow mesenchymal stem cells (BM-MSCs) are important for postnatal angiogenesis and are suitable for use in construction of blood vessels by tissue engineering. The present study aimed to investigate the influence of recombination signal binding protein for immunoglobulin kappa $\mathrm{J}$ region (RBP-JK) on the differentiation of BM-MSCs into vascular endothelial cells, and to assess the underlying mechanisms. BM-MSCs were isolated and identified by flow cytometry. Lentiviral vectors encoding RBP-JK shRNA (shRBPJK) were constructed to knockdown RBP-JK expression and endothelial differentiation of BM-MSCs was induced. The experimental groups were treated with: empty lentiviral vector (vector group), growth factors (bFGF and VEGF; induced group), shRBPJK (shRBPJK group), and growth factors + shRBPJK (induced + shRBPJK group). The expression of endothelial markers, vascular endothelial growth factor receptor 2 (Flk-1), and von Willebrand factor (vWF) were detected by immunofluorescence. Additionally, in vitro blood vessel formation and phagocytosis were assessed using acetylated LDL, Dil complex and the underlying molecular mechanisms evaluated by western blotting. BM-MSCs were separated and transduced with shRBPJK to reduce RBP-JK expression. Compared with the vector group, the expression of the endothelial cell markers, Flk-1 and vWF, in vitro tubule formation, and phagocytosis ability increased, while the expression levels of p-AKT/AKT and $\mathrm{p}-\mathrm{NF}-\kappa \mathrm{B} / \mathrm{NF}-\kappa \mathrm{B}$ were significantly decreased $(\mathrm{P}<0.05)$ in the induced, shRBPJK, and induced + shRBPJK groups. Compared with the induced group, the expression of Flk-1 and vWF, the number of tubules, and phagocytosis were higher
\end{abstract}

Correspondence to: Dr Xifu Shang, Department of Orthopaedic Surgery, Anhui Provincial Hospital, 17 Lujiang Road, Hefei, Anhui 230001, P.R. China

E-mail: shangxifuchina@163.com

*Contributed equally

Key words: RBP-JK, bone marrow mesenchymal stem cells, endothelial cells in the induced + shRBPJK group, while the expression levels of $\mathrm{p}-\mathrm{AKT} / \mathrm{AKT}$ and $\mathrm{p}-\mathrm{NF}-\kappa \mathrm{B} / \mathrm{NF}-\kappa \mathrm{B}$ were lower $(\mathrm{P}<0.05)$. Collectively, the present data indicated that silencing of RBP-JK promotes the differentiation of MSCs into vascular endothelial cells, and this process is likely regulated by $\mathrm{AKT} / \mathrm{NF}-\kappa \mathrm{B}$ signaling.

\section{Introduction}

Angiogenesis is necessary for repair of defects in bone tissue. Allogeneic bone or tissue engineered bone transplantation is the most commonly used method used to repair large bone defects $(1,2)$; however, ischemic necrosis often occurs, due to the lack of vascularization in the central part of the tissue, leading to failure of bone defect repair (3).

Bone marrow mesenchymal stem cells (BM-MSCs) are important for postnatal angiogenesis and are suitable for use in tissue engineering to construct blood vessels (4). BM-MSCs are pluripotent adult stem cells, which can be obtained from bone marrow, in addition to hematopoietic stem cells. BM-MSCs originate from bone marrow stromal tissue and participate in the formation of the bone marrow microenvironment. These cells can differentiate into osteocytes, chondrocytes, adipocytes, muscle cells, and fibroblasts in response to different induction conditions in vitro $(5,6)$. Furthermore, BM-MSCs can differentiate into vascular components, including vascular endothelial cells and vascular smooth muscle cells (7). In vivo and in vitro studies have demonstrated that BM-MSCs participate in neovascularization by secreting angiogenic factors (8). Moreover, in vitro experiments demonstrate that the combination of vascular endothelial growth factor and basic fibroblast growth factor (bFGF) can induce BM-MSCs to differentiate into endothelial cells and express corresponding cell markers (9).

Recombination signal binding protein for immunoglobulin kappa $\mathbf{J}$ region (RBP-JK) is a factor important for induction of MSC proliferation and can also act as an inhibitor of MSC differentiation during development (10). A recent study demonstrated that the Notch signaling pathway is a regulator of bone formation (11). The Notch1 receptor releases the activated intracellular Notch1 domain (N1-ICD/ICN-1) after hydrolysis by $\gamma$-secretase. Then, N1-ICD transfers to target genes, including Msx2, HES1, and Heyl/2, in the nucleus and binds 
to the transcription inhibitor, RBP-JK (12). The upregulation of target genes is involved in the growth and development of various tissues in embryonic development and during pathological processes in various tissues and organs in adults (13).

In the present study, the effects of silencing of RBP-JK on the differentiation of BM-MSCs into vascular endothelial cells were investigated. The present results provide an experimental basis for the clinical treatment of bone defects using BM-MSCs.

\section{Materials and methods}

Animals. Sprague-Dawley specific-pathogen-free (SPF) grade rats ( $n=20$, approximately $120 \mathrm{~g}, 2-3$ weeks old, male) were purchased from Changzhou Cavens Laboratory Animal Co., Ltd., under license No. SCXK (Su) 2016-0010. Rats were housed under SPF conditions, and were automatically maintained at a temperature of $23^{\circ} \mathrm{C} \pm 2^{\circ} \mathrm{C}$, a relative humidity of 45-65\%, in a controlled 12-h light/dark cycle, and had access to food and water ad libitum. All experimental protocols were supervised by the Ethics Committee of Anhui Provincial Hospital (Hefei, China).

Preparation of BM-MSCs. Rats were sacrificed by cervical dislocation following anesthesia with isoflurane (5\% for induction and $1 \%$ for maintenance). When there was no heartbeat, femurs and tibia were collected, immersed in $75 \%$ ethanol for $5 \mathrm{~min}$, and adherent muscle tissues were removed by sterile isolation. Bone marrow cavities were exposed, washed repeatedly with PBS, and cell washing solution was collected and screened to form single cell suspensions. Bone marrow cells were collected by centrifugation ( $870 \mathrm{x} \mathrm{g}, 5 \mathrm{~min})$. Cells were suspended in DMEM medium (Gibco; Thermo Fisher Scientific, Inc.) containing 10\% fetal bovine serum (FBS), inoculated in culture dishes at a density of $2 \times 10 \% / \mathrm{cm}^{2}$, and cultured in a $37^{\circ} \mathrm{C} \mathrm{CO}_{2}$ incubator. Cell suspensions were then centrifuged at $930 \mathrm{x} \mathrm{g}$ for $3 \mathrm{~min}$, and supernatants were discarded. Cell types were detected by flow cytometry using antibodies against CD34 (cat. no. 11-0341-82), CD105 (cat. no. 17-1057-42), and CD90 (cat. no. 14-0900-81, all from Thermo Fisher Scientific, Inc.).

Construction of the shRBPJK vector. Three pairs of shRNA oligonucleotides were designed by Shanghai GenePharma Co., Ltd., based on the sequence of the RBP-JK gene (Table I).

Cell transduction. A PLVshRNA-EGFP (2A) Puro vector (VL3103; Beijing Yingmao Shengye Biotechnology Co., Ltd.) was digested by $\mathrm{BamHI} / E c o \mathrm{RI}$ at $37^{\circ} \mathrm{C}$. The shRNA sequences were integrated into the vector according to the protocol: Pre-denaturation at $95^{\circ} \mathrm{C}$ for $5 \mathrm{~min}, 84^{\circ} \mathrm{C}$ for $5 \mathrm{~min}, 74^{\circ} \mathrm{C}$ for $5 \mathrm{~min}$ and $72^{\circ} \mathrm{C}$ for $5 \mathrm{~min}$, and then maintenance at $4^{\circ} \mathrm{C}$. Lentiviruses encoding shRBPJK were established as previously described (14). At $60 \%$ confluence, cells were transduced with the aforementioned lentiviruses (Shanghai GenePharma

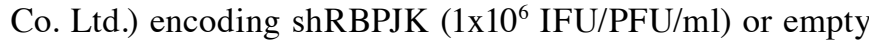
vector (Shanghai GenePharma Co. Ltd.) using Polybrene (Invitrogen; Thermo Fisher Scientific, Inc.). Twenty-four hours after transduction, the medium was replaced with fresh DMEM, and cells were incubated in a $\mathrm{CO}_{2}$ incubator $\left(5 \% \mathrm{CO}_{2}\right)$ at $37^{\circ} \mathrm{C}$ for $48 \mathrm{~h}$. RBP-JK mRNA and protein expression were detected by quantitative real-time PCR and western blotting, respectively.

Quantitative real-time polymerase chain reaction ( $q R T-P C R$ ). Cells were seeded in 6-well plates. After transduction for $48 \mathrm{~h}$, mRNA was extracted using a TRIzol assay kit (Baosheng Science \& Technology Innovation Co, Ltd.). According to the kit instructions, mRNA was transcribed into cDNA (cat. no. 639522, Takara Biotechnology Co., Ltd.) and fluorescence quantitative PCR was used to determine the expression levels of targeted genes, using cDNA as a template. The expression levels of $R B P-J K$ were normalized to those of $G A P D H$. Primers are listed in Table II. Reactions included $9.5 \mu \mathrm{l}$ RNase-free $\mathrm{dH}_{2} \mathrm{O}, 1 \mu \mathrm{l}$ cDNA/DNA, $2 \mu \mathrm{l}$ primers, and $12.5 \mu \mathrm{l} 2 \mathrm{X}$ ULtraSYBR Mixture, and were conducted using the following temperature cycles: $95^{\circ} \mathrm{C}$ (denaturation) $10 \mathrm{sec}$, $56^{\circ} \mathrm{C}$ (annealing) $30 \mathrm{sec}$, and $72^{\circ} \mathrm{C}$ (extension) $30 \mathrm{sec}$, for 40 cycles.

Experimental groups. Cells were divided into four experimental groups, treated with: i) Lentiviral vector only (vector group), ii) growth factors (10 ng/ml bFGF + $50 \mathrm{ng} / \mathrm{ml}$ VEGF; induced group), iii) lentivirus encoding RBP-JK-targeting shRNA (shRBPJK group), and iv) growth factors + lentivirus encoding shRBPJK (induced + shRBPJK group). For growth factor induction, the original culture medium was discarded and the induction solution (DMEM + FBS + $10 \mathrm{ng} / \mathrm{ml} \mathrm{bFGF}$ $+50 \mathrm{ng} / \mathrm{ml} \mathrm{VEGF}$ ) was added to the BM-MSCs, as previously described (9). The induction solution was changed every three days for ten consecutive days. Rat bFGF (cat. no. P1020-500) and rat VEGF (cat.no. CJ96) were purchased from Novoprotein.

Immunofluorescence. The cells were fixed using $4 \%$ polyformaldehyde (PFA) for $15 \mathrm{~min}$, washed with PBS three times for 3 min each, and permeated with $0.5 \%$ Triton X-100 at room temperature for $20 \mathrm{~min}$. Cells were then blocked with $5 \% \mathrm{BSA}$ at $37^{\circ} \mathrm{C}$ for $30 \mathrm{~min}$, followed by the addition of primary antibodies and incubation overnight at $4^{\circ} \mathrm{C}$. Primary antibodies were Flk-1 (1:500; cat. no. bs-10412R; Bioss Antibodies, Inc.) and von Willebrand factor (vWF) (1:400; product code ab6994; Abcam). After washing in PBS, fluorescent secondary antibody Cy3 (1:200, BA1032, Wuhan Boster Biological Technology, Ltd.) was added and cells were incubated at $37^{\circ} \mathrm{C}$ for $30 \mathrm{~min}$. Samples were then incubated with DAPI for $5 \mathrm{~min}$ to stain the nuclei.

In vitro angiogenesis assay. Matrix glue (250 $\mu \mathrm{l})$ was added into each well of a 24-well plate and uniformly distributed. Cells were starved for $2 \mathrm{~h}$ in serum-free medium and BM-MSCs digested and resuspended at a density of $5 \times 10^{5} / \mathrm{ml}$. Aliquots of cell suspensions $(10 \mu \mathrm{l})$ were added to each well. The time until tube formation was monitored and images were captured using a microscope (BX51; Olympus Corpotation).

Phagocytosis of acetylated LDL, Dil complex. Acetylated LDL, Dil complex (Dil-ac-LDL) was added into M199 medium containing $10 \%$ FBS to a final concentration of $10 \mu \mathrm{g} / \mathrm{ml}$ to assess phagocytosis. After culture for $24 \mathrm{~h}$ to allow cell adherence, Dil-ac-LDL was added to each experimental group and 
Table I. Sequences of shRBPJK.

ShRBPJK Sequence (5'-3')

shRBPJK-F1

ShRBPJK-R1

shRBPJK-F2

shRBPJK-R2

shRBPJK-F3

shRBPJK-R3
GATCCGCAAGCGGATAAAGGTCATCTCTTCCTGTCAGAAGATGACCTTTATCCGCTTGCTTTTTG AATTCAAAAAGCAAGCGGATAAAGGTCATCTTCTGACAGGAAGAGATGACCTTTATCCGCTTGCG GATCCGCACTCCCAAGACTGATAATTCTTCCTGTCAGAAATTATCAGTCTTGGGAGTGCTTTTTG AATTCAAAAAGCACTCCCAAGACTGATAATTTCTGACAGGAAGAATTATCAGTCTTGGGAGTGCG GATCCGCCGAAACAATGTACAGATGTCTTCCTGTCAGAACATCTGTACATTGTTTCGGCTTTTTG AATTCAAAAAGCCGAAACAATGTACAGATGTTCTGACAGGAAGACATCTGTACATTGTTTCGGCG

shRBPJK, RBP-JK shRNA; F, forward; R, reverse.

Table II. Primer sequences.

\begin{tabular}{llccc}
\hline Genes & \multicolumn{1}{c}{ Sequence $\left(55^{\prime}-3^{\prime}\right)$} & Primer length $(\mathrm{bp})$ & Product length $(\mathrm{bp})$ & Annealing $\left({ }^{\circ} \mathrm{C}\right)$ \\
\hline$R B P-J K \mathrm{~F}$ & CTTAGCAAGCGGATAAAGGTC & 21 & 386 & 58 \\
$R B P-J K \mathrm{R}$ & TTGTGGAGTTGTGATACAGGGT & 22 & & 58.6 \\
GAPDH F & GCAAGTTCAACGGCACAG & 18 & 141 & 5 \\
GAPD $\mathrm{R}$ & CGCCAGTAGACTCCACGAC & 19 & &
\end{tabular}

$R B P-J K$, recombination signal binding protein for immunoglobulin kappa $\mathrm{J}$ region; $\mathrm{F}$, forward; $\mathrm{R}$, reverse.
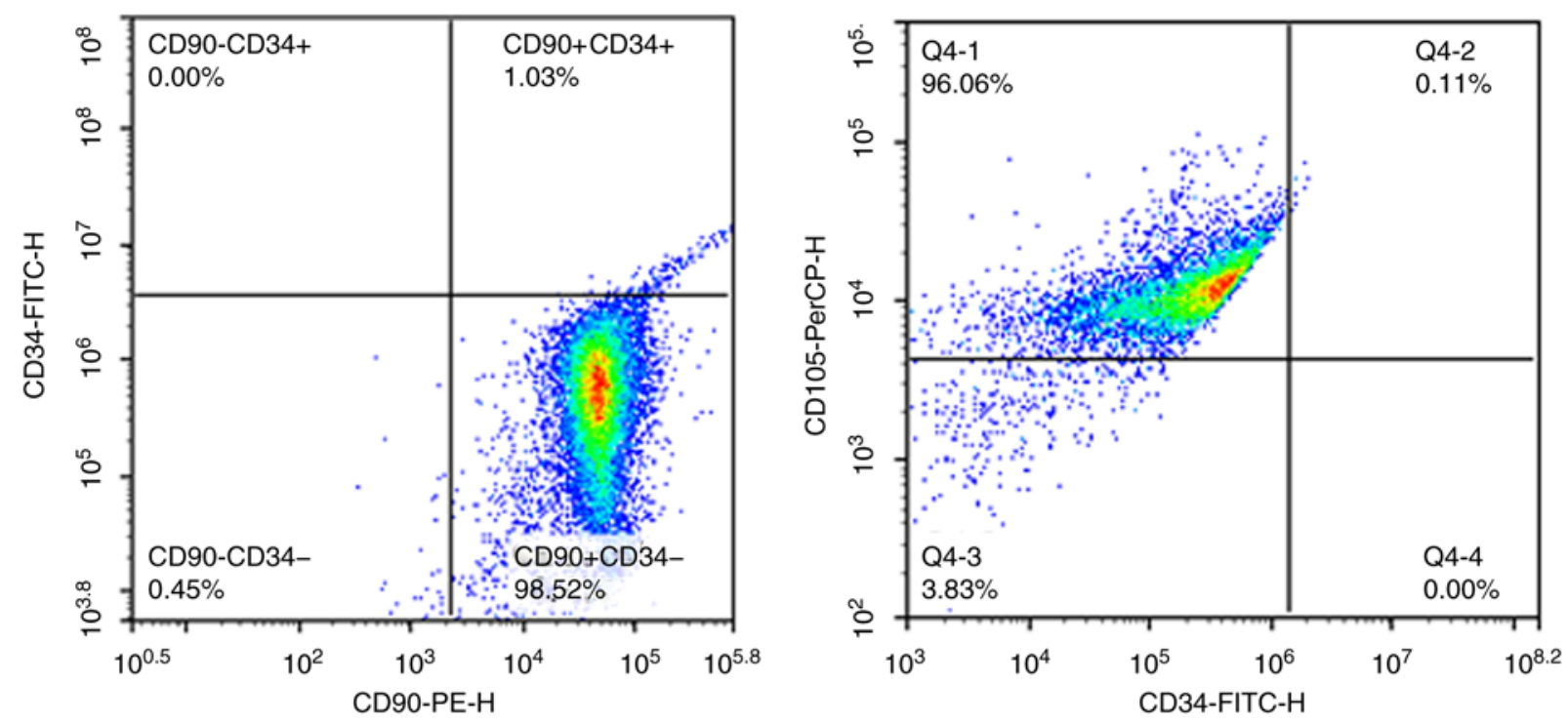

Figure 1. Identification of BM-MSCs. The majority of cells were $\mathrm{CD} 90^{+} \mathrm{CD} 105^{+} \mathrm{CD} 34$. BM-MSCs, bone marrow mesenchymal stem cells.

cells were then incubated at $37^{\circ} \mathrm{C}$, in $5 \% \mathrm{CO}_{2}$, for $24 \mathrm{~h}$, washed twice with PBS, fixed in $4 \%$ PFA, and observed under a fluorescence microscope (BX51).

Western blotting. After transduction and/or induction, proteins were extracted from cells for western blotting using a ReadyPrep protein isolation kit (GE Healthcare Life Sciences). Extracted proteins were quantified with a bicinchoninic acid protein assay kit and separated by $12 \%$ SDS-PAGE ( $25 \mu \mathrm{g} /$ lane). After transferring onto nitrocellulose membranes, the membranes were blocked with 5\% skimmed milk. Membranes were then incubated with mouse monoclonal anti-GAPDH $(1 / 2,000$; TA-08; ZS-BIO; OriGene Technologies, Inc.), rabbit monoclonal anti-RBP-JK (1/5,000; product code ab180588, Abcam), anti-AKT (1/5,000; cat. no. 4691, CST), anti-p-AKT (1/5,000; cat. no. 9271, CST), anti-NF-кB (1/5,000; cat. no. 6956; CST), or anti-p-NF- $\kappa \mathrm{B}(1 / 1,000$; cat. no. sc-136548; Santa Cruz Biotechnology, Inc.) overnight at $4^{\circ} \mathrm{C}$. Secondary antibody (1/1,000; product code ab131368, Abcam) was then added and incubated for 1-2 $\mathrm{h}$ at room temperature. ECL exposure liquid droplets (cat. no. RPN2133; GE Healthcare Life Sciences) were then added to the membranes. Finally, the membranes were 

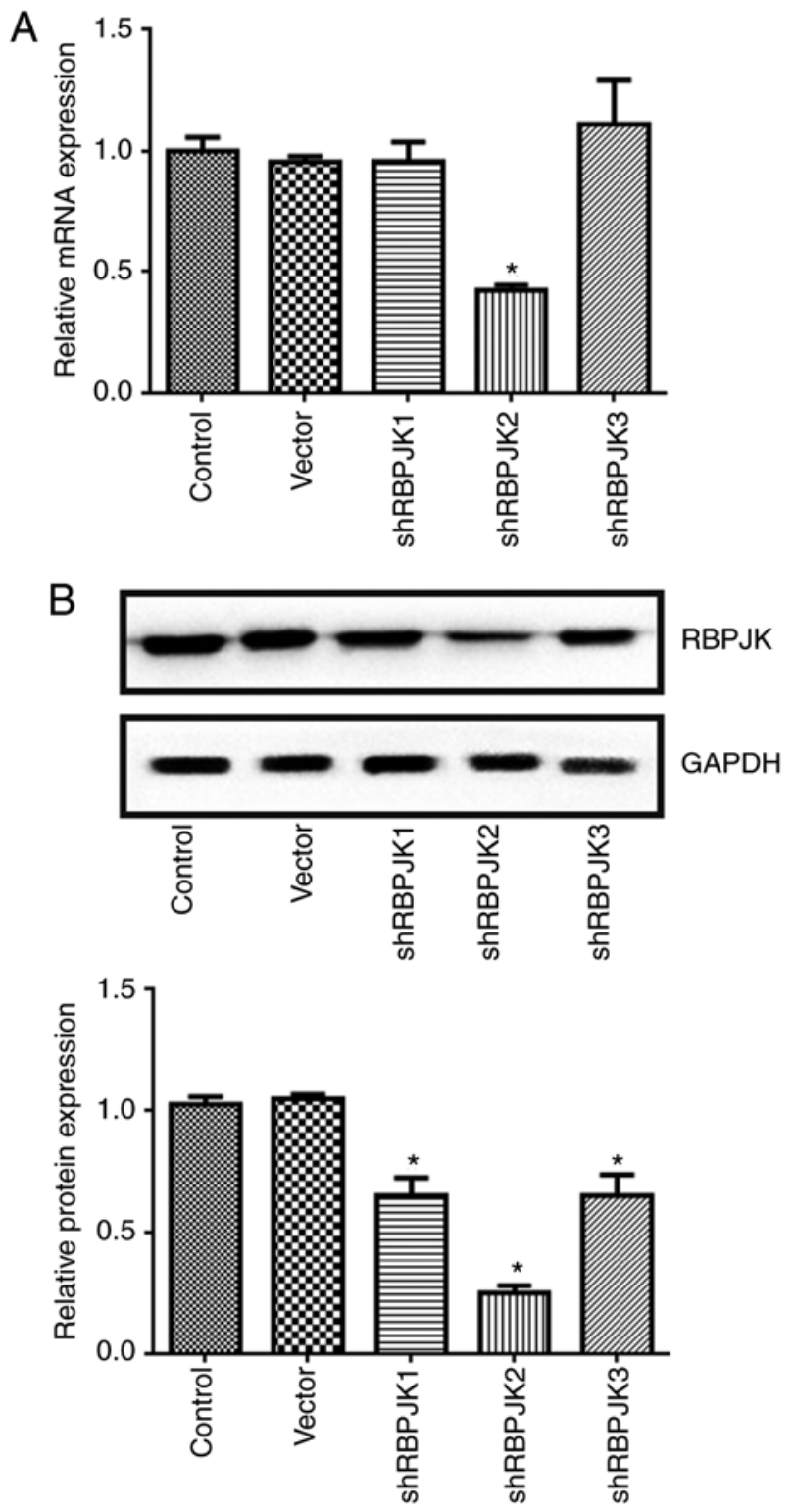

Figure 2. Verification of the interference effect of shRBPJK. (A) RBP-JK mRNA levels. (B) RBP-JK protein levels. shRBPJK2 had the optimal influence on the expression of RBP-JK. Upper panel: Representative blots. Lower panel: quantification data. ${ }^{*} \mathrm{P}<0.05$, compared with the control group. RBP-JK, recombination signal binding protein for immunoglobulin kappa J region; shRBPJK, RBP-JK shRNA.

exposed using a gel imaging system (Bio-Rad Laboratories, Inc.). Grayscale density of bands was analyzed using Quantity One analysis software v1.4.6 (Bio-Rad Laboratories, Inc.).

Statistical analysis. Data are presented as the means and standard deviation, and were analyzed using SPPSS 17.0 (SPSS, Inc.). The significance of differences was evaluated using a one-way ANOVA with post-hoc Newman-Keuls test, and $\mathrm{P}$-values $<0.05$ were considered to indicate a statistically significant difference.

\section{Results}

Isolation and identification of BM-MSCs. The results of isolation and identification of BM-MSCs are presented in Fig. 1.
The majority of isolated cells were $\mathrm{CD} 90^{+} \mathrm{CD} 105^{+} \mathrm{CD} 34^{-}$, indicating that they were BM-MSCs.

Detection of RBP-JK knockdown. The results of fluorescence quantitative PCR (Fig. 2A) and western blotting (Fig. 2B) revealed that RBP-JK expression was significantly lower in cells treated with shRBPJK2 than that in the control group $(\mathrm{P}<0.05)$; therefore, shRBPJK2 was selected for use in subsequent experiments.

shRBPJK promotes the expression of endothelial cell markers. The expression levels of the endothelial cell markers, Flk-1 and vWF, were significantly higher in the induced and shRBPJK groups than that in the vector control group $(\mathrm{P}<0.05)$. In addition, the expression levels of Flk-1 and vWF were significantly higher in the induced + shRBPJK group than those in the induced group $(\mathrm{P}<0.05)$ (Fig. 3).

shRBPJK promotes angiogenesis in vitro. The results of in vitro angiogenesis assays are presented in Fig. 4. Compared with the vector control group, the numbers of tubes in all other groups were significantly greater $(\mathrm{P}<0.05)$. Furthermore, relative to the induced group, the number of tubes was significantly increased in the induced + shRBPJK group $(\mathrm{P}<0.05)$.

shRBPJK promotes Dil-ac-LDL phagocytosis. Endothelial cells can mediate phagocytosis of ac-LDL, by binding to scavenger receptors on their surface, while LDL receptors distributed on other cells cannot ingest ac-LDL (15); therefore, in an attempt to identify vascular endothelial cells, their ability to absorb Dil-ac-LDL was assessed. The results of the Dil-ac-LDL phagocytosis assay are presented in Fig. 5. Compared with the vector control group, the positive rate of low density lipoprotein phagocytosis was significantly increased in all other groups $(\mathrm{P}<0.05)$. Furthermore, compared with the induced group, the rate of phagocytosis was significantly higher in the induced + shRBPJK group $(\mathrm{P}<0.05)$.

shRBPJK reduces phosphorylation of $A K T$ and $N F-\kappa B$. Compared with the vector control group, levels of $\mathrm{p}-\mathrm{AKT} / \mathrm{AKT}$ and $\mathrm{p}-\mathrm{NF}-\kappa \mathrm{B} / \mathrm{NF}-\kappa \mathrm{B}$ were significantly decreased in all other groups $(\mathrm{P}<0.05)$. Furthermore, compared with the induced group, the expression levels of $\mathrm{p}-\mathrm{AKT} / \mathrm{AKT}$ and $\mathrm{p}-\mathrm{NF}-\kappa \mathrm{B} / \mathrm{NF}-\kappa \mathrm{B}$ were significantly lower in the induced + shRBPJK group $(\mathrm{P}<0.05)$ (Fig. 6).

\section{Discussion}

In the present study, evidence was generated that silencing of RBP-JK not only promotes the differentiation of MSCs into vascular endothelial cells, but also facilitates VEGF- and bFGF-induced endothelial differentiation. Moreover, the present data demonstrated that this effect may be regulated by the AKT/NF- $\mathrm{B}$ signaling pathway.

The repair of bone defects using allogeneic or tissue engineered bone depends on the establishment of close spatial and temporal connections between blood vessels and bone cells; hence, angiogenesis is fundamental to the process of bone healing. Therefore, methods to promote angiogenesis and reconstruct local blood supply, as soon as possible 
A
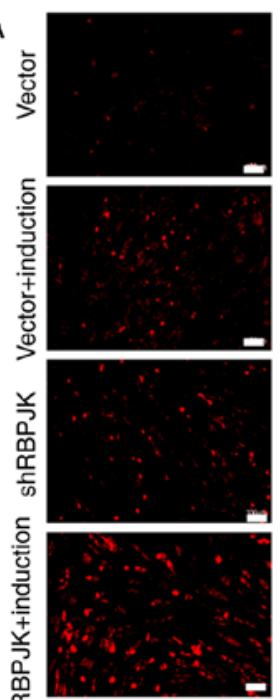

Flk-1
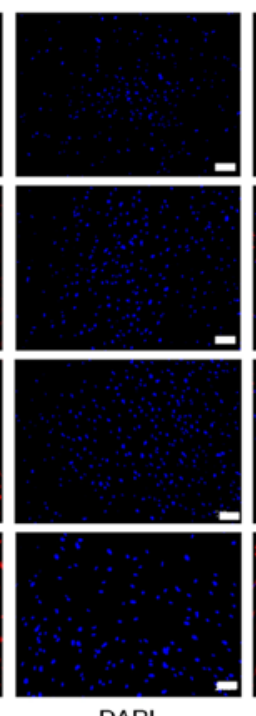

DAPI
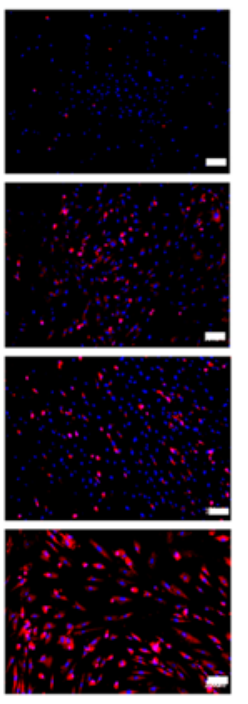

Merged
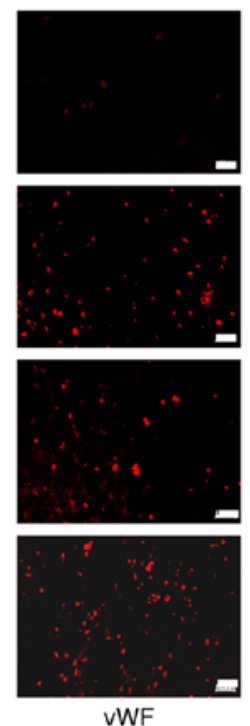

vWF
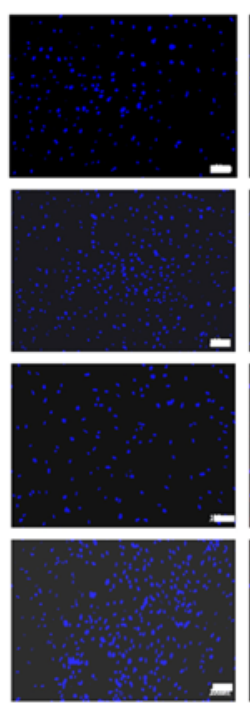

DAPI
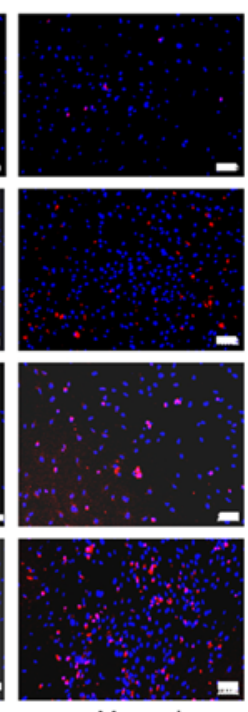

Merged

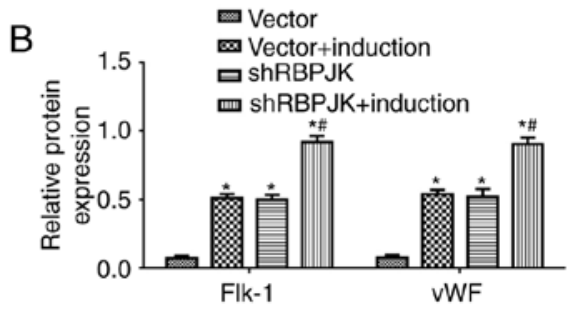

Figure 3. The expression of endothelial cell surface markers. (A) Representative images of Flk-1 and vWF expression. Left panel: Flk-1 expression. Right panel: vWF expression. (B) Quantification data for Flk-1 and vWF expression. ${ }^{*} \mathrm{P}<0.05$, compared with the vector control group; ${ }^{*} \mathrm{P}<0.05$, compared with the induced group. Scale bars, $100 \mu \mathrm{m}$. Flk-1, vascular endothelial growth factor receptor 2; vWF, von Willebrand factor; shRBPJK, RBP-JK shRNA.

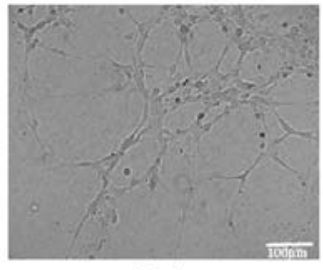

Vector

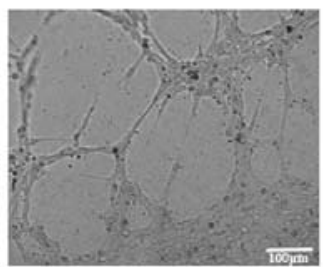

ShRBPJK

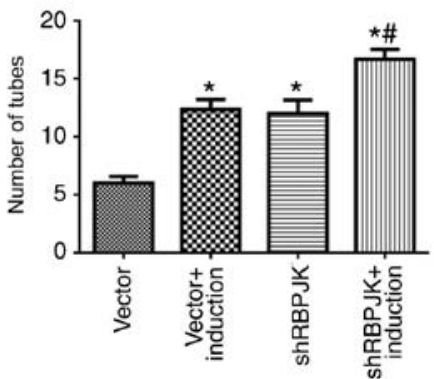

Figure 4. Results of in vitro angiogenesis assay. Upper panel: representative images. Lower panel: Quantification data. ${ }^{*} \mathrm{P}<0.05$, compared with the vector control group; ${ }^{\prime} \mathrm{P}<0.05$, compared with the induced group. Scale bars, $100 \mu \mathrm{m}$. shRBPJK, RBP-JK shRNA.

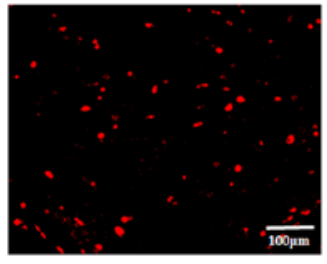

Vector

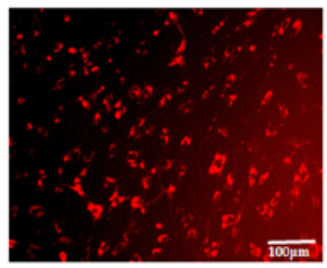

ShRBPJK

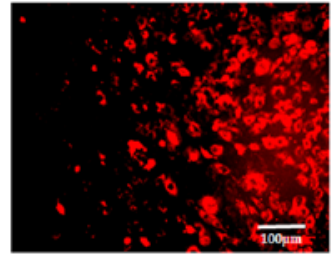

Vector+induction

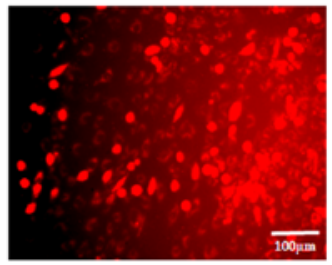

shRBPJK+induction

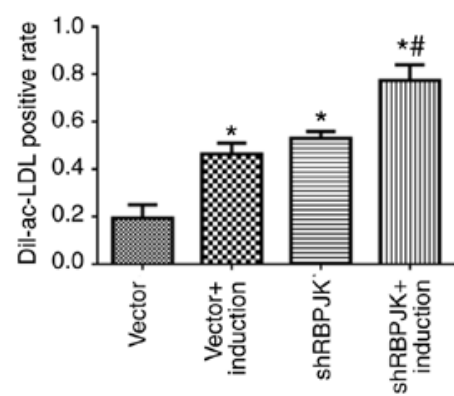

Figure 5. Dil-ac-LDL phagocytosis assay. Upper panel: representative images. Lower panel: Quantification data. ${ }^{*} \mathrm{P}<0.05$, compared with the vector control group; ${ }^{\#} \mathrm{P}<0.05$, compared with the induced group. Scale bars, $100 \mu \mathrm{m}$. shRBPJK, RBP-JK shRNA. 
A
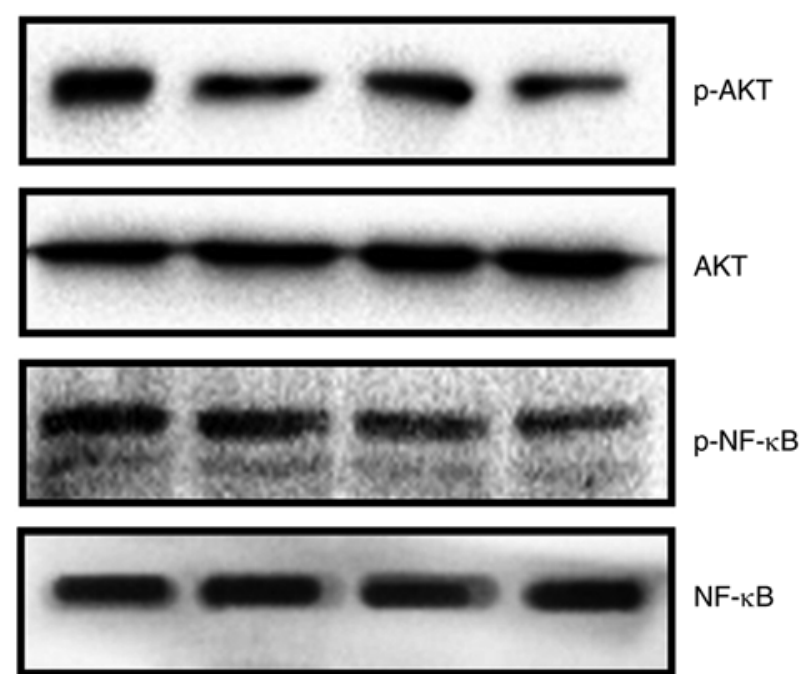

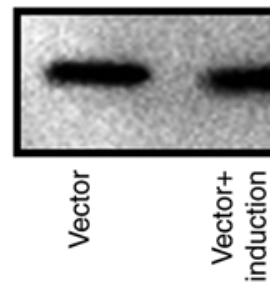

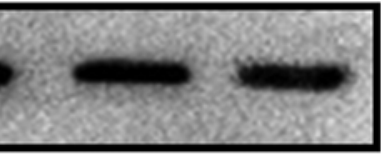

奠

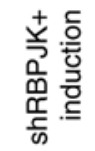

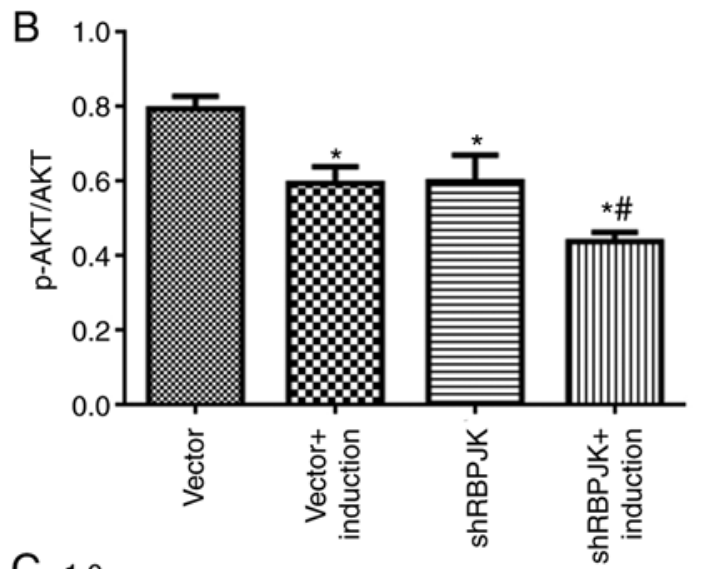

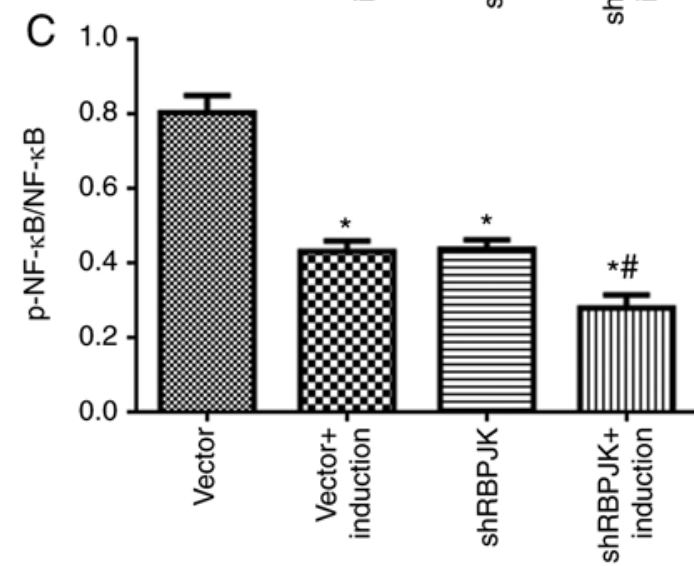

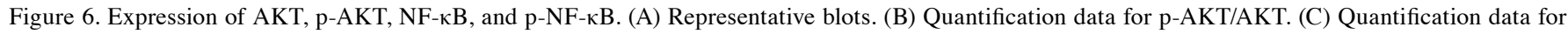
$\mathrm{p}-\mathrm{NF}-\kappa \mathrm{B} / \mathrm{NF}-\kappa \mathrm{B}$. "P<0.05, compared with the vector control group; ${ }^{\mathrm{P}} \mathrm{P}<0.05$, compared with the induced group. shRBPJK, RBP-JK shRNA.

after allogeneic bone or tissue engineered bone implantation into bone defects, are currently of particular research interest (16). MSCs can be induced to transform into vascular endothelial cells and smooth muscle cells (17). Furthermore, human BM-MSCs cultured in vitro can differentiate into endothelial-like cells after 7 days of induction in medium containing VEGF and bFGF (18); the induced cells express the endothelial surface markers, Flk-1 (KDR), Flt-1, and vWF, and exhibit in vitro angiogenesis ability (19). MSCs transplanted into animals differentiate into endothelial cells and smooth muscle cells, participate in angiogenesis, and improve blood supply (20). In the present study, MSCs were isolated and identified by flow cytometry; resulting in cells that were $\mathrm{CD}^{+}{ }^{+} \mathrm{CD}_{105}{ }^{+} \mathrm{CD} 34-$, indicating that the isolated cells were BM-MSCs. The prepared BM-MSCs were used to determine the effects of RBP-JK silencing on endothelial differentiation.

RBP-JK protein is expressed in MSCs and has an important role in their proliferation (21). In the present study, RBP-JK was knocked down in BM-MSCs. Factors commonly used to induce the differentiation of MSCs into endothelium in vitro include VEGF, bFGF, insulin-like growth factor, and transforming growth factor- $\beta$, among others. (22). As the most important cytokine in vascular endothelial cells, VEGF functions to increase capillary permeability, promote endothelial cell proliferation, and induce angiogenesis (23). In the present study, a combination of VEGF and bFGF was used to induce MSC differentiation into endothelial cells. The present results revealed that the expression of the endothelial markers, Flk-1 and vWF, on the cell surface were increased, both after induction with $50 \mathrm{ng} / \mathrm{ml} \mathrm{VEGF}$ and $10 \mathrm{ng} / \mathrm{ml} \mathrm{bFGF}$ and by RBP-JK silencing. Moreover, RBP-JK silencing further promoted the endothelial differentiation induced by $50 \mathrm{ng} / \mathrm{ml}$ VEGF and $10 \mathrm{ng} / \mathrm{ml} \mathrm{bFGF}$. These results indicated that the transformation of BM-MSCs into endothelial cells can be induced by knocking down RBP-JK, and that there is a synergistic effect of induction using growth factors and knockdown of RBP-JK.

The number of tubules generated was increased by growth factor-induced endothelial differentiation and by silencing of RBP-JK, and there was a synergistic effect between growth factor-induction and shRBP-JK silencing. These results indicated that knocking down RBP-JK can promote endothelial mitosis, induce the formation of new vascular networks, and has an important role in the differentiation and proliferation of endothelial cells. Endothelial cells can proliferate, and form new blood vessel networks in vitro and in vivo (24,25). In addition, the present study revealed that both growth factor induction and shRBPJK could increase the ability of cells to phagocytose ac-LDL, and that these two methods had a synergistic effect. These results indicated that the ability to take up ac-LDL is another method that can be used to identify endothelial cells.

$\mathrm{NF}-\kappa \mathrm{B}$ is a key factor involved in the regulation of cellular gene transcription and is activated by oxygen free radicals (26). Upon activation, the transcription of $\mathrm{NF}-\kappa \mathrm{B}$ p 65 and $\mathrm{NF}-\kappa \mathrm{B}$ $\mathrm{P} 50$ increase, and the transcription and protein expression of various proinflammatory factors are elevated, resulting in enhanced cell adhesion, inflammation, cell differentiation, and 
degradation of the extracellular matrix (27). AKT has an important role in the structure and function of endothelial cells (28). In addition, AKT can phosphorylate a series of nuclear factors to induce the release of $\mathrm{NF}-\kappa \mathrm{B}$ and regulate gene transcription $(29,30)$. The present study revealed that levels of $\mathrm{p}$-AKT and $\mathrm{p}-\mathrm{NF}-\kappa \mathrm{B}$ decreased after growth factor-induced endothelial differentiation and knocking down RBP-JK, and that this decrease was more significant when endothelial induction and RBP-JK silencing were performed simultaneously. The AKT/NF- $\mathrm{KB}$ signaling pathway is also related to endothelial differentiation (31), and the present results indicated that RBP-JK-induced endothelial cell formation and angiogenesis may be mediated by $\mathrm{AKT} / \mathrm{NF}-\kappa \mathrm{B}$ signaling.

There are still some limitations to the present study. On the one hand, although the molecular mechanisms underlying the differentiation of bone marrow mesenchymal stem cells into vascular endothelial cells were revealed, the application of RBP-JK modified MSCs in animals with bone defect still requires confirmation. On the other hand, how Akt/NF- $\mathrm{BB}$ signaling pathway is involved in the process requires more elucidation.

In conclusion, the silencing of RBP-JK promotes differentiation of MSCs into vascular endothelial cells, and is likely regulated by the $\mathrm{AKT} / \mathrm{NF}-\kappa \mathrm{B}$ signaling pathway.

\section{Acknowledgements}

Not applicable.

\section{Funding}

The present study was supported by the Provincial Natural Science Foundation of Anhui (grant no. 1808085QH242).

\section{Availability of data and materials}

The datasets used and/or analyzed during the present study are available from the corresponding author on reasonable request.

\section{Authors' contributions}

ZL, YD, MC, CZ, KW, GL and XS performed the experiments and analyzed the data. ZL and YD designed the study and wrote the manuscript. All authors read and approved the manuscript and agree to be accountable for all aspects of the research in ensuring that the accuracy or integrity of any part of the work are appropriately investigated and resolved.

\section{Ethics approval and consent to participate}

All animal procedures were approved by the Ethics Committee of Anhui Provincial Hospital (Hefei, China).

\section{Patient consent for publication}

Not applicable.

\section{Competing interests}

The authors declare that they have no competing interests.

\section{References}

1. Wang W and Yeung KWK: Bone grafts and biomaterials substitutes for bone defect repair: A review. Bioact Mater 2: 224-247, 2017.

2. Henkel J, Woodruff MA, Epari DR, Steck R, Glatt V, Dickinson IC, Choong PF, Schuetz MA and Hutmacher DW: Bone regeneration based on tissue engineering conceptions-A 21st century perspective. Bone Res 1: 216-248, 2013.

3. Socie G, Selimi F, Sedel L, Frija J, Devergie A, Esperou Bourdeau H, Ribaud P and Gluckman E: Avascular necrosis of bone after allogeneic bone marrow transplantation: Clinical findings, incidence and risk factors. Br J Haematol 86: 624-628, 1994.

4. Bing W, Pang X, Qu Q, Bai X, Yang W, Bi Y and Bi X: Simvastatin improves the homing of BMSCs via the PI3K/AKT/miR-9 pathway. J Cell Mol Med 20: 949-961, 2016.

5. Zheng H, Zou W, Shen J, Xu L, Wang S, Fu YX and Fan W: Opposite effects of coinjection and distant injection of mesenchymal stem cells on breast tumor cell growth. Stem Cells Transl Med 5: 1216-1228, 2016.

6. Bianco P, Robey PG and Simmons PJ: Mesenchymal stem cells: Revisiting history, concepts, and assays. Cell Stem Cell 2: 313-319, 2008.

7. Kang ML, Kim JE and Im GI: Vascular endothelial growth factor-transfected adipose-derived stromal cells enhance bone regeneration and neovascularization from bone marrow stromal cells. J Tissue Eng Regen Med 11: 3337-3348, 2017.

8. Zou D, Zhang Z, He J, Zhang K, Ye D, Han W, Zhou J, Wang Y, $\mathrm{Li}$ Q, Liu X, et al: Blood vessel formation in the tissue-engineered bone with the constitutively active form of HIF-1 $\alpha$ mediated BMSCs. Biomaterials 33: 2097-2108, 2012.

9. Cao Y, Sun Z, Liao L, Meng Y, Han Q and Zhao RC: Human adipose tissue-derived stem cells differentiate into endothelial cells in vitro and improve postnatal neovascularization in vivo. Biochem Biophys Res Commun 332: 370-379, 2005.

10. Wang YC, Wang SH, Wei YN, Du DW, Xu H, Gao CC, Zheng MH, Xie J, Li JC, Dong GY, et al: Notch-RBP-J signaling is required by bone marrow stromal cells for the treatment of acute graft versus host disease. Stem Cell Res 11: 721-735, 2013.

11. Lee SY and Long F: Notch signaling suppresses glucose metabolism in mesenchymal progenitors to restrict osteoblast differentiation. J Clin Invest 128: 5573-5586, 2018.

12. Blain J, Bedard J, Thompson M, Boisvert FM and Boucher MJ: C-terminal deletion of NOTCH1 intracellular domain ( $1^{\mathrm{ICD}}$ ) increases its stability but does not amplify and recapitulate $\mathrm{N} 1^{\mathrm{ICD}}$-dependent signalling. Sci Rep 7: 5034, 2017.

13. Yu L, Liang H, Lu Z, Zhao G, Zhai M, Yang Y, Yang J, Yi D, Chen W, Wang $\mathrm{X}$, et al: Membrane receptor-dependent Notch1/Hes1 activation by melatonin protects against myocardial ischemia-reperfusion injury: In vivo and in vitro studies. J Pineal Res 59: 420-433, 2015.

14. Xu W, Cao J, Zhou Y, Wang L and Zhu G: GPR30 activation improves memory and facilitates DHPG-induced LTD in the hippocampal CA3 of middle-aged mice. Neurobiol Learn Mem 149: 10-19, 2018.

15. Sharma D, Hamlet SM, Petcu EB and Ivanovski S: The effect of bisphosphonates on the endothelial differentiation of mesenchymal stem cells. Sci Rep 6: 20580, 2016.

16. Xie C, Reynolds D, Awad H, Rubery PT, Pelled G, Gazit D, Guldberg RE, Schwarz EM, O'Keefe RJ and Zhang X: Structural bone allograft combined with genetically engineered mesenchymal stem cells as a novel platform for bone tissue engineering. Tissue Eng 13: 435-445, 2007.

17. Zhu F, Guo GH, Chen W and Wang NY: Effects of bone marrow-derived mesenchymal stem cells engraftment on vascular endothelial cell growth factor in lung tissue and plasma at early stage of smoke inhalation injury. World J Emerg Med 1: 224-228, 2010.

18. Adibfar A, Amoabediny G, Baghaban Eslaminejad M, Mohamadi J, Bagheri F and Zandieh Doulabi B: VEGF delivery by smart polymeric PNIPAM nanoparticles affects both osteogenic and angiogenic capacities of human bone marrow stem cells. Mater Sci Eng C Mater Biol Appl 93: 790-799, 2018.

19. Cattaneo F, Castaldo M, Parisi M, Faraonio R, Esposito G and Ammendola R: Formyl peptide receptor 1 modulates endothelial cell functions by NADPH Oxidase-dependent VEGFR2 transactivation. Oxid Med Cell Longev 2018: 2609847, 2018. 
20. Wang H, Ding XG, Yang JJ, Li SW, Zheng H, Gu CH, Jia ZK and Li L: LncRNA MIAT facilitated BM-MSCs differentiation into endothelial cells and restored erectile dysfunction via targeting miR-200a in a rat model of erectile dysfunction. Eur J Cell Biol 97: 180-189, 2018.

21. Shang X, Luo Z, Wang X, Jaeblon T, Marymont JV and Dong Y: Deletion of RBPJK in mesenchymal stem cells enhances osteogenic activity by Up-regulation of BMP signaling. PLoS One 10: e0135971, 2015.

22. Dalley A, Smith JM, Reilly JT and Neil SM: Investigation of calmodulin and basic fibroblast growth factor (bFGF) in idiopathic myelofibrosis: Evidence for a role of extracellular calmodulin in fibroblast proliferation. Br J Haematol 93: 856-862, 1996.

23. Adini A, Adini I, Chi ZL, Derda R, Birsner AE, Matthews BD and D'Amato RJ: A novel strategy to enhance angiogenesis in vivo using the small VEGF-binding peptide PR1P. Angiogenesis 20 399-408, 2017.

24. Staton CA, Reed MW and Brown NJ: A critical analysis of current in vitro and in vivo angiogenesis assays. Int J Exp Pathol 90: 195-221, 2009.

25. Jin K, Li B, Lou L, Xu Y, Ye X, Yao K, Ye J and Gao C: In vivo vascularization of MSC-loaded porous hydroxyapatite constructs coated with VEGF-functionalized collagen/heparin multilayers. Sci Rep 6: 19871, 2016.

26. Long L, Pang XX, Lei F, Zhang JS, Wang W, Liao LD, Xu XE, He JZ, Wu JY, Wu ZY, et al: SLC52A3 expression is activated by $\mathrm{NF}-\kappa \mathrm{B}$ p65/Rel-B and serves as a prognostic biomarker in esophageal cancer. Cell Mol Life Sci 75: 2643-2661, 2018.
27. Zhu L, Chen T, Chang X, Zhou R, Luo F, Liu J, Zhang K, Wang Y, Yang Y, Long H, et al: Salidroside ameliorates arthritis-induced brain cognition deficits by regulating $\mathrm{Rho} / \mathrm{ROCK} / \mathrm{NF}-\kappa \mathrm{B}$ pathway. Neuropharmacology 103: 134-142, 2016.

28. Ou HC, Chou WC, Chu PM, Hsieh PL, Hung CH and Tsai KL: Fucoxanthin protects against oxLDL-induced endothelial damage via activating the AMPK-Akt-CREB-PGCl $\alpha$ pathway. Mol Nutr Food Res 63: e1801353, 2019.

29. Kalantary-Charvadeh A, Sanajou D, Hemmati-Dinarvand M, Marandi Y, Khojastehfard M, Hajipour H, Mesgari-Abbasi M, Roshangar L and Nazari Soltan Ahmad S: Micheliolide protects against doxorubicin-induced cardiotoxicity in mice by regulating PI3K/Akt/NF- $\kappa \mathrm{B}$ signaling pathway. Cardiovasc Toxicol 19: 297-305, 2019.

30. Song Z, Chen H, Xu W, Wu S and Zhu G: Basolateral amygdala calpain is required for extinction of contextual fear-memory. Neurobiol Learn Mem 155: 180-188, 2018.

31. Cho JS, Kang JH, Park IH and Lee HM: Steroids inhibit vascular endothelial growth factor expression via TLR4/Akt/NF- $\kappa \mathrm{B}$ pathway in chronic rhinosinusitis with nasal polyp. Exp Biol Med (Maywood) 239: 913-921, 2014.

(7) $(2)$ This work is licensed under a Creative Commons Attribution-NonCommercial-NoDerivatives 4.0 International (CC BY-NC-ND 4.0) License. 